\title{
Informal Economy and Urbanization of West African Economic and Monetary Union (UEMOA) Cities
}

\author{
Aïcha $^{1 *}$ TIENDREBEOGO Aïchatou ${ }^{*}$ MOURFOU $^{1} \quad$ Issa $^{* *}$ SAWADOGO ${ }^{2}$ \\ 1.University of Ouaga 2, Burkina Faso \\ 2.Pan-African University of Governance of Humanities and Social Sciences (PAUGHSS) / University of \\ Yaoundé 2, Cameroun
}

\begin{abstract}
Urbanization is a growing phenomenon in the UEMOA countries, in a context of the increasing informalization of its economies. Based on these facts, this research set out to analyze the relationship between urbanization and the size of the informal economy. This research uses the Pooler Mean Group (PMG) model to analyze the effects of urbanization on informality, and the Panel Threshold Regression (PTR) model for nonlinear analysis. It appears that the rate of urbanization has a positive effect on the size of the informal economy. Also, that the quality of institutions can reduce the above positive effect, reducing the rate of urbanization.
\end{abstract}

Keywords: Informal economy, Urbanization, Institution, PMG estimate, PTR estimate.

DOI: $10.7176 / \mathrm{DCS} / 10-12-05$

Publication date: December $31^{\text {st }} 2020$

\section{Introduction}

Sub-Saharan Africa is one of the regions where the informal economy weighs the most with an average of around 38\% of GDP between 2010 and 2014 against 34\% for Southeast Asia and 23\% for Europe (Medina and Schneider, 2018). The WAEMU countries are not left out. In fact, the contribution of the informal sector to GDP represents more than $50 \%$ of the overall added value of GDP, more than $80 \%$ of total employment and more than $90 \%$ of newly created jobs in these countries (Mbaye, 2014). . Also, the informal sector is the main provider of jobs in developing countries. As Charmes (2010) notes, the informal sector accounts for between $65 \%$ and $80 \%$ of urban employment in the capitals of WAEMU countries.

These facts notwithstanding, it appears that urbanization is another phenomenon common to developing countries. . Indeed, the World Bank's report on urbanization in Africa admits that urbanization is a growing and worrying phenomenon. According to this same report, the urban population in Africa currently stands at 472 million inhabitants, but it will double over the next twenty-five years, reaching one billion inhabitants in 2040 . Also, he specifies that as soon as 2025, African cities will be home to an additional 187 million inhabitants, equivalent to the current population of Nigeria (World Bank, 2017). In the case of cities in WAEMU countries, the urbanization of these cities is increasing. In fact, the urbanization rate of the area increased from $33.04 \%$ on average per year over the period 2000-2010 to nearly $40 \%$ over the period 2011-2019. This growing urbanization is the source of various problems. Indeed, migrants are confronted with problems of housing, employment etc., all of which lead to a deterioration in the standard of living. Also, this phenomenon creates the expansion of slums, inadequate infrastructure, rising rent costs, insecurity etc.

These facts lead us to ask the question whether this growth urbanization is not the basis of the growing informalisation of the countries of the zone. This research therefore sets itself the objective of determining the role of urbanization in the development of informality. This relationship which seems to be analyzed very little in the literature, particularly with regard to the WAEMU countries. It will shed light on the political authorities on the consequences of urbanization at the economic level. The research is organized as follows: first we present the theoretical and empirical literature on the relationship between urbanization and informality, then we present the stylized facts for the study area, and finally we present the methodology and results of the research.

\section{Literature}

The relationship between urbanization and the informal sector is established in both theoretical and empirical literature. Indeed, on a theoretical level, according to authors such as Harris and Todaro (1969), migrants go to the city in the hope of finding a good job in the formal sector. But there, the difficulty of integrating into the formal sector led them to take up informal jobs. It should be noted that it is difficult for rural people, who are mostly inexperienced and qualified, to be able to find formal employment. As Cole and Sanders (1985) note it can take 50 years. As a result, many of the new city dwellers are never able to move to the formal sector, leading to congestion in the informal sector. Therefore, as urbanization continues, it often results in a large informal labor force. The shift from the rural informal sector to the urban informal sector can be explained by several pull and push factors. In many cases, the urban informal sector offers better opportunities than the rural sector. Incomes may be higher in urban informal employment than in rural occupations, and urban areas tend to provide better public services due to an urban bias in policies (Lipton, 1976). Even in cases where the conditions 
between two sectors are similar, many individuals prefer the urban informal sector in the hope of finding a future employment opportunity in the formal sector (Banerjee, 1983). Also, according to Todaro (1997), rural-urban migration is the source of growing unemployment and therefore large size of informality. Indeed, he explains that the growing urbanization of African cities is at the root of the rise in unemployment rates. These unemployed people, for the most part unskilled, develop small activities to survive, which leads to an increase in informal activities. It also appears that although the formal sector may not create enough jobs for new city dwellers, people still prefer to migrate to cities, which stimulates the growth of the informal economy (Elgin and Oyvat, 2013). Cole and Sanders (1985) provide a further analysis on the issue. They admit that the growth of the formal urban sector increases the demand for the products of the urban subsistence sector. As a result, urban living wages would increase, which would increase the urban and rural subsistence wage gap. Hence, migration would be stimulated. Safa (1986) reviews the historical process of urbanization and industrialization in Latin America resulting from changes in the mode of incorporation into the capitalist world economy from the colonial period to the contemporary period. She finds that the growth of the urban informal economy in Latin America is the result of the international division of labor, which has forced many countries to increasingly turn to export manufacturing to alleviate their external debt and the current economic crisis. It shows that the majority of manufacturing production takes place through the informal sector. Because the latter is able to produce more cheaply by using more vulnerable segments of the workforce, such as women, and bypassing labor laws designed to protect workers such as minimum wages, social benefits and adequate working conditions.

Empirically, Gundogan and Bicerli (2009) show that the rapid and uncontrolled migration created by the displacement of the population from rural to urban areas poses serious problems from a labor market perspective. The increase in rural-urban migration flows contributes to a greater supply of urban labor. This growing supply of labor has produced an increasing urban unemployment rate and a deterioration in the quality of employment, leading to increasing rates of informal employment. According to these authors, one of the most distinctive features of the economies of developing countries is the fact that more than half of workers are employed in the urban informal sector. They find that urbanization and the informal sector are phenomena which evolve in the same direction. In other words, for these authors, an increase in urbanization leads to an increase in the size of the informal sector. Elgin and Oyvat (2013) examine the empirical relationship between the level of urbanization and the size of the informal economy using cross-national datasets, representing GDP and sector employment shares of informal urban. Their results indicate that there is an inverted U-shaped relationship between informality and the level of urbanization. In other words, the share of the informal sector increases in the early stages of urbanization due to several pull and push factors; however, it tends to drop in the later stages. Rauch (1993) had obtained the same results for the countries of Latin America.

\section{Stylized facts}

This analysis presents the graphical analysis and the descriptive analysis for the case of UEMOA.

\section{- Graphical analysis}

The graph below shows the evolution of the urbanization rate and the size of the informal economy in the area, over the period 1996 to 2017. It appears that the urbanization rate has an increasing trend throughout study period. As for the size of the informal economy, it is changing up and down. Indeed, over the period 1991-1993, there was an increase in the size of the informal sector. On the other hand, over the period 1993 to 2015, we note a downward trend in the size of informality in the area. Finally, over the 2015-2017 period, we note a resumption of informality in the area. 

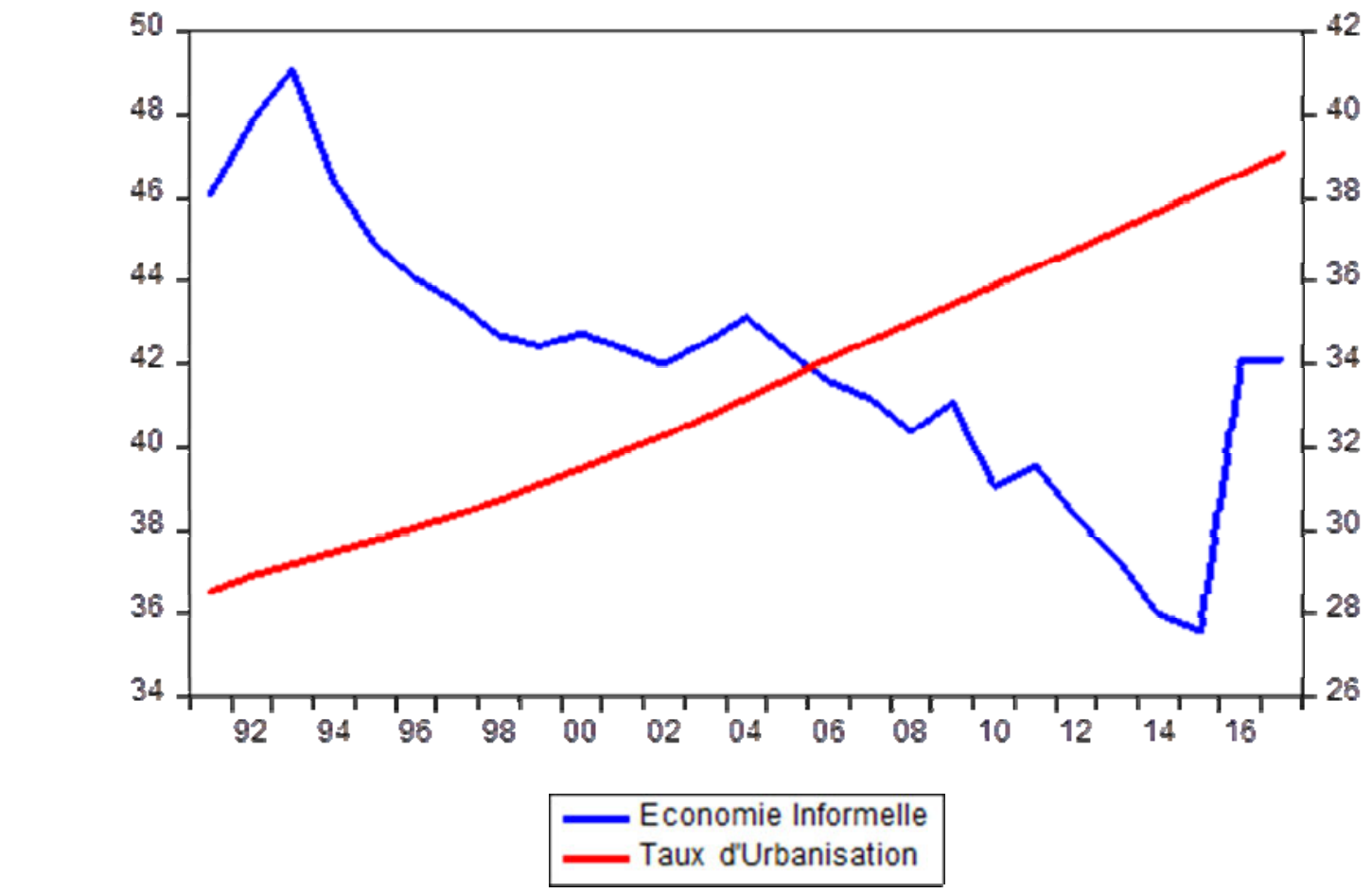

Graph: Joint evolution of the urbanization rate and the size of the informal economy in the UEMOA zone over the period 1991-2017

Source: author using data from WDI (2018), IMF (2018)

\section{- Descriptive analysis}

Table 1 shows the results of the descriptive analysis. The table shows that informality is an important part of the economies of the zone. Indeed, it appears that the average size of the informal economy in the WAEMU zone represents $42.07 \%$ of GDP. This size varies between $29.4 \%$ and $60.8 \%$ over the period 1996 to 2017 . This is not negligible. The average urbanization rate of $33.41 \%$. This rate varies between $14.07 \%$ and $50.32 \%$. The average per capita income in the area is 288,909 Fr CFA. Tax revenues represent on average $11.95 \%$ of GDP. The average unemployment rate for the area is $3.84 \%$. This rate is relatively low, but does not represent the actual current situation. Indeed, the definition of the unemployment rate adopted is that of the International Labor Office (ILO), which does not respond to the realities of developing countries such as those in the area. The average primary school enrollment rate is $76.01 \%$ over the study period. As for the quality of public institutions, on a scale of 0 to 1 , it is on average equal to 0.47 for the zone.

Table 1: Descriptive analysis

\begin{tabular}{llllll}
\hline Variables & Observations & \multicolumn{1}{c}{ Moyenne } & Ecart Type & \multicolumn{1}{c}{ Minimum } & \multicolumn{1}{c}{ Maximum } \\
\hline Informal Economy & 189 & 42,0754 & 6,619121 & 29,45 & 60,8 \\
Urbanization Rate & 189 & 33,4101 & 10,89869 & 14,07 & 50,326 \\
GDP per Capta & 189 & 288909,9 & 156421,6 & 130646,9 & 767297,7 \\
Taxation & 189 & 11,95693 & 5,215633 & 3,109143 & 28,0206 \\
Unemployement & 189 & 3,848349 & 2,603612 & 0,32 & 11,71 \\
Credit & 189 & 16,43778 & 7,724096 & 3,302083 & 39,38639 \\
Education & 183 & 76,01118 & 27,46384 & 26,4657 & 132,4683 \\
Agriculture & 189 & 29,75393 & 8,336963 & 11,97997 & 44,14365 \\
Institutions & 189 & 0,4725163 & 0,078214 & 0,2615734 & 0,6132592 \\
\hline
\end{tabular}

Source: author using data from WDI (2018), IMF (2018)

\section{Methodology}

This part proposes the specification of the theoretical and empirical model, the variables used and the data source and estimation techniques.

\subsection{Theoretical model}

The literature on the determinants of the informal economy is based on the Shleifer and Vishny (1993) model, which relates corruption and the development of the informal economy. Indeed, their model served as a theoretical and empirical framework (Choi and Thum, 2005; Rei and Bhattacharya, 2008; Dreher and Schneider, $2009 \ldots$... with some extensions. Thus, the theoretical analysis function is defined as follows: 


$$
I E=\mathscr{Y}\left(U R_{i} \mathscr{Z}_{i}\right)
$$

Where IE is the size of the informal economy, UR is the rate of urbanization and a set of variables that influence the informal sector.

\subsection{Linear model specification}

By specifying the theoretical model described above as a panel, the linear equation to be estimated is as follows:

$$
\begin{aligned}
& I E_{i t}=\text { 钱 }+\beta_{j} U R_{j, i t}+\sum_{l=1}^{6} \beta_{l} Z_{l, i t}+\varepsilon_{i t} \\
& I E_{i t}=\text { 钱 }+\beta_{j} U R_{i t}+\beta_{k} I N S T_{\mathrm{k}, i t}+\sum_{l=1}^{6} \beta_{l} Z_{l, i t}+\varepsilon_{i t}
\end{aligned}
$$

\subsection{Non-linear or regime change model $\checkmark$ Model presentation}

This section proposes a multi-regime modeling approach, initially proposed by Hansen (1999), which allows thresholds to be introduced in a static panel regression (Panel Threshold Regression: PTR). In these models, a transition mechanism takes place between the different regimes. This type of model makes it possible not only to determine the number of regimes for a variable, but also to estimate the threshold levels and the marginal impact of this variable.

\section{Hansen model (1999) with two regimes (one threshold)}

The general formulation of Hansen's model (1999) applied to this research and satisfying a PTR representation is as follows:

$$
I E_{\mathrm{it}}=?_{\mathrm{i}} \quad \beta_{1}^{\prime} \mathrm{x}_{\mathrm{it}}+\beta_{2}^{\prime} \mathrm{x}_{\mathrm{it}} \mathrm{I}\left(\mathrm{q}_{\mathrm{it}} ; \gamma\right)+\varepsilon_{\mathrm{it}}
$$

Where $I E_{\mathrm{it}}$ is the dependent variable, $\mu_{i}$ individual fixed effects, $\beta_{1}$ et $\beta_{2}$ parameter vectors $K \times 1$, $\mathrm{I}\left(q_{i t} ; \gamma\right)$ denotes the transition function associated with transition variables $\left(I N S T_{i t}\right)$ and a threshold parameter vector $\gamma_{;} x_{i t}$ is a vector of explanatory variables not containing the lagged explained variable; and $\varepsilon_{i t}$ the error term independently and identically distributed $\left(0 ; \sigma_{\varepsilon}^{2}\right)$. The two-regime Hansen model can therefore be written as follows:

$$
\mathrm{y}_{\mathrm{it}}=?_{\mathrm{i}} \quad \beta_{1}^{\prime} \mathrm{x}_{\mathrm{it}} \mathrm{I}\left(\mathrm{q}_{\mathrm{it}} \leq \gamma\right)+\beta_{2}^{\prime} \mathrm{x}_{\mathrm{it}} \mathrm{I}\left(\mathrm{q}_{\mathrm{it}}>\gamma\right)+\phi^{\prime} \mathrm{z}_{\mathrm{it}}+\varepsilon_{\mathrm{it}}
$$

In this last equation, is the set of variables whose associated coefficients do not undergo a change from one regime to another.

The process has two stages. The first step is to calculate the threshold value of institutional quality and the second to determine the number of threshold or regime change. Referring to Bayale (2017), we must first test the model for successive candidate values of $\gamma$ by sequential least squares; the one that minimizes the sum of the squared residuals is chosen as the threshold value of institutional quality around which the regime change takes place. This can be expressed under the following constraint:

$$
\hat{\gamma}=\operatorname{argmin} S_{n}(\gamma)
$$

According to several studies (Hansen, 1999; Bayale, 2017), critical values are estimated to determine the 95\% confidence interval of the cut-off value for institutional quality, depending on the relationship:

$\Gamma=\{\gamma: \operatorname{LR}(\gamma) \leq C(\alpha)\}$

$L R(\gamma)$ gives an asymptotic distribution of the likelihood ratio statistic, while $C(\alpha)$ showing $95 \%$ of this distribution.

\section{$\checkmark$ Econometric analysis}

The inferences on the threshold models relate to tests of linearity, determination of the number of regimes and the construction of a confidence interval. The linearity test consists in showing that the threshold is statistically significant, and that the relationship between the variables can be represented according to a regime change model. This amounts to testing in equation (3.15) the null hypothesis $H_{0}: \beta_{1}=\beta_{2}$ against the alternative 
hypothesis $H_{1}: \beta_{1} \neq \beta_{2}$. The decision is made based on the following likelihood ratio statistic: $L R_{1}=\frac{S_{0}-S_{1}\left(\hat{\gamma}_{1}\right)}{\hat{\sigma}^{2}}$ where $S_{0}$ is the sum of the squares of the linear model residuals and $S_{1}\left(\hat{\gamma}_{1}\right)$ the sum of the squares of the one-threshold model residuals.

The test to determine the number of plans is applied in the presence of a proven threshold effect. The test procedure is similar to that of the linearity test. This is for example to test whether the model has two speeds or at least three speeds, and so on. The following statistic is constructed: $L R_{2}=\frac{S_{1}\left(\text { 浑 }-S_{2}\left(\gamma_{1}, \gamma_{2}\right)\right.}{\hat{\sigma}^{2}}$ where $S_{2}$ is the sum of the squares of the residuals of the three-regime model. The null hypothesis of a single threshold is rejected in favor of a minimum of two, if the value of $L R_{2}$ is greater than the critical values. The process should continue to determine the maximum number of plans. When the threshold effect is proven and the threshold number is determined, Hansen (1999) shows that the thresholds $\hat{\gamma}_{j}$ are convergent estimators of the true values, and that the asymptotic distribution of these is nonstandard.

\subsection{Preliminary tests on the data}

This part presents the dependency tests, unit root test, cointegration test, Hausman specification test.

\section{$\checkmark$ Dependency test}

Niang (2011) explains that not taking into account a possible interindividual dependence in the data generation process can affect the results of stationarity and causality. To anticipate this eventuality, we perform various tests, namely the dependency tests.

Annex Table 1 presents the results of the dependency tests (statistics from tests by Friedman (1937), Frees (1995), and Pesaran (2004)) for the model residuals. The results of the tests of independence at the level of the residuals and the variables do not allow the null hypothesis of independence between the individuals in the panel to be rejected (the probabilities associated with the tests are all greater than 0.05 ). Therefore, the stationarity studies are based on the first generation ${ }^{1}$ tests.

\section{$\checkmark$ Unit root test}

The study of long-term relationships on panel data requires taking into account the problem of stationarity. To overcome this problem, a series of unit root tests has become a common approach for multivariate analysis on panel data. As the individual dependency hypothesis has not been accepted, first generation unit root tests will be used.

Appendix Table 2 shows the results of the unit root tests of Im, Pesaran and Shin (IPS, 2003) and Levin, Lin and Chu (LLC). We can deduce that the variables EI and INST are stationary in level. On the other hand, the variables TU, PIBh, TAX, TC, CI and EDU, are non-stationary and integrated of order one (I (1)). It is therefore necessary to check, if there is a bonus on board, a long-term relationship between the dependent variable and the explanatory variables.

\section{$\checkmark$ Cointegration test}

Analogously to time series, the problem of spurious regression arises in the study of panel data. These tests, under the assumption of no cointegration, are based on the residuals of the estimates of the long-run relationship. As the results of the dependence tests have concluded that there is independence between the residues, the first generation Pedroni test can be used.

Annex Table 3 shows the cointegration tests of Pedroni (1999, 2004). Note that the hypothesis of noncointegration is not rejected at the $5 \%$ threshold, for the panel v, panel rho, panel PP, panel ADF, group PP and group ADF tests. Only the rho group test rejects the null hypothesis of non-cointegration. It therefore appears that the variables are cointegrated.

\section{$\checkmark$ Hausman test}

The panel therefore contains nonstationary and cointegrated variables. This led us to use a heterogeneous and non-stationary panel estimation model. The use of Pooled Mean Group (PMG) or Mean Group (MG) estimators is recommended for this purpose. These estimation methods are proposed respectively by Pesaran et al. (1999). These methods have a comparative advantage over conventional methods, because they allow the introduction of heterogeneity into certain coefficients to be estimated. Indeed, the PMG method assumes that the long-term coefficients of all countries are not significantly different, but on the other hand allows the short-term coefficients to be different. As for the MG method, it is used when the long-term coefficients are heterogeneous. The choice between the PMG and MG estimator is made by performing a Hausman specification test.

\footnotetext{
${ }^{1}$ If the null hypothesis of independence between the individuals in the panel were accepted, the unit root and cointegration tests would have focused on the second generation tests.
} 
The probabilities of the Hausman statistics for the four (04) specifications of the model are all greater than the critical threshold of 0.05 (see Table 4 in the appendix). The null hypothesis of long-term homogeneity of the variables cannot therefore be rejected. So there are no noticeable long-term differences between the coefficients. The coefficients of the PMG estimator are therefore used because they are more appropriate.

\section{$\checkmark$ Result of linearity test}

The results of the linearity and number of regimes tests are presented in Table 5 of the appendix. They show that the nonlinearity hypothesis is validated, due to the fact that the probabilities associated with LR tests are below the critical threshold of 5\% a threshold. It also implies that there are two regimes in the relationship between the informal economy and urbanization, taking into account the level of institutions. It therefore appears that there is a given level that the quality of institutions must reach, so that urbanization is no longer a driver of informality. This threshold is 0.576 . This means that the effect of urbanization on informality also depends on the quality of institutions.

\subsection{Empirical model}

The empirical model PMG to be estimated to analyze the linear effect of the urbanization rate on the size of the informal economy is therefore as follows:

$$
\Delta \mathrm{IE}_{i t}=\varphi_{i}\left(\mathrm{IE}_{i t-1}-\theta_{i}^{\prime} x_{i t}-\delta_{1 i} U R_{i t-1}-\delta_{12} \mathrm{Z}_{i t-1}\right)-\sum_{j=0}^{n} \delta^{*^{\prime \prime}}{ }_{i j} X_{i t}-\Delta \delta_{1 i} U R_{i t-1}-\Delta \delta_{12} \mathrm{Z}_{i t-1}+\mu_{i}+\tau d_{i t}+\varepsilon_{i t}
$$

The linearity test shows that there is only one threshold. We can therefore specify the following empirical PTR model, to analyze the nonlinear effect of urbanization on informality:

$I E_{\mathrm{it}}=?_{\mathrm{i}} \quad \beta_{1}^{\prime} U R_{\mathrm{it}} \mathrm{I}\left(\mathrm{INST}_{\mathrm{it}} \leq \gamma_{1}\right)+\beta_{2}^{\prime} U R_{\mathrm{it}} \mathrm{I}\left(\mathrm{INST}_{\mathrm{it}}>\gamma_{2}\right)+\phi^{\prime} \mathrm{z}_{\mathrm{it}}+\varepsilon_{\mathrm{it}}$

EI is the dependent variable represented by the size of the informal sector or informal economy as a percentage of GDP. It is calculated using the MIMIC (Multiple Indicators Multiple Causes) econometric method. An increase in this variable also reflects a relatively larger size of the informal sector in the country. It is one of the most used measures and commonly recognized as reflecting the extent of informality in a country (Johnson et al, 2000; Schneider and Enste, 2000; Botero et al., 2004; Dreher, Schneider, 2006; Torgler and Schneider, 2009; Rei and Bhattacharya, 2008; Ouédraogo, 2017; Medina and Schneider, 2018). Source: Médina and Schneider, (IMF, 2018).

UR: the urbanization rate, it represents the percentage of the urban population in the total population. According to authors such as Johnson et al. (2000), Friedman et al. (2000), Galli and Kucera (2004), the rate of urbanization is the factor that explains the development of the informal economy.

INST: represents the institutional variable. The KKZ corruption control variable is used in this research.

The discussion of the link between corruption and the development of the informal sector in the theoretical literature is not consensual. Rose-Ackerman (1997) finds that informality and corruption are substitutable. While Hindriks et al. (1999) argue that corruption between taxpayers and tax officials leads to undervaluation of the tax burden and leaks into the informal sector. Johnson et al (2000) and Friedman et al. (2000) explain that corruption leads to lower tax revenues in the formal economy and a deterioration in the quality of public administration. These facts therefore dissuade the incentive of agents to remain in the formal. They conclude that corruption drives the expansion of the informal sector. Therefore, one would expect a negative or positive relationship between corruption control and the size of the informal sector. Institutional data comes from the World Bank / World Governance Indicators database (BM / WGI, 2018).

$\mathbf{Z}$ represents a set of variables influencing the size of the informal sector or control variables (real GDP per capita (GDPh)), domestic credit to the private sector (CI), tax revenue as a percentage of GDP (TAX)), unemployment rate (TC), Johnson et al. (2000), Friedman et al. (2000), Galli and Kucera (2004), as well as Dreher and Schneider (2009), Rei and Bhattacharya (2008), Torgler and Schneider (2009), and Dreher et al. (2009), establish a relationship between the size of the informal sector and these variables. Data on the other variables come from the World Bank's World Development indicators (WDI / BM, 2018).

\section{Results}

This part presents the short-term, long-term analysis of the effects of urbanization on growth as well as the nonlinear analysis of the conditional relationship between urbanization, the

\section{$\checkmark$ Short term results}

The results of the short-term analysis are shown in Table 2 below. It appears that the rate of urbanization has no short-term effect on the size of the informal economy. On the other hand, the coefficient associated with real GDP per capita is negative and significant at the $1 \%$ threshold in both specifications. This means that an increase in real GDP per capita leads to a decrease in the size of the informal economy in the short run. 
Table 2: Results of the short-term analysis

\begin{tabular}{lllll}
\hline VARIABLES & EI & EI & ISEI & ISEI \\
\hline \multirow{2}{*}{ Urbanization rate } & 1,617 & $-6,768$ & 19.78 & 0.938 \\
& $(3,871)$ & $(6,498)$ & $(25.50)$ & $(5.916)$ \\
Real GDP per capita & $-0,000167^{* * *}$ & $-0,000161^{* * *}$ & $-0.000177^{* * *}$ & $-9.22 \mathrm{e}-05^{* * *}$ \\
& $(2,96 \mathrm{e}-05)$ & $(2,61 \mathrm{e}-05)$ & $(2.67 \mathrm{e}-05)$ & $(3.48 \mathrm{e}-05)$ \\
Taxation & 0,154 & 0,198 & -0.0768 & 0.343 \\
Unemployment & $(0,157)$ & $(0,173)$ & $(0.203)$ & $(0.262)$ \\
& 36,88 & 31,44 & 40.44 & 11.00 \\
Education & $(36,32)$ & $(30,87)$ & $(40.10)$ & $(8.229)$ \\
& 0,181 & 0,155 & $0.409 * * *$ & $0.368 * *$ \\
credit & $(0,126)$ & $(0,124)$ & $(0.137)$ & $(0.175)$ \\
Agriculture & 0,0219 & $-0,0348$ & -0.0621 & 0.0812 \\
& $(0,0952)$ & $(0,108)$ & $(0.169)$ & $(0.180)$ \\
Institutions & $-0,0952$ & $-0,0903$ & $-0.318 *$ & 0.0158 \\
& $(0,0979)$ & $(0,0914)$ & $(0.187)$ & $(0.0651)$ \\
& & -7.729 & & 2.773 \\
& & $(10.06)$ & & $(19.84)$ \\
\hline
\end{tabular}

Source: author using data from IMF (2018), WDI (2018) and WGI (2018)

Standard deviations are in parentheses

$\checkmark$ Long term result

$(*),(* *),(* * *)$ Significant at $10 \%, 5 \%$ and $1 \%$ respectively

The results of the long-term analysis are presented in the table below. It appears that the error correction coefficient is negative and significant at the rate of $1 \%$ for both specifications. This implies that the long term results are valid. Specification 1 (column 1) presents the results of the effects of urbanization on the informal economy. We see that the coefficient associated with the urbanization rate variable is positive and significant at the $5 \%$ threshold. In other words, if the urbanization rate increases by $1 \%$, the size of the informal economy increases by $0.80 \%$. Also, the coefficient associated with real GDP per capita is positive and significant at the $5 \%$ level. It also appears that the coefficient associated with the unemployment rate is positive and significant at the $10 \%$ level. Specifically, a rise in the unemployment rate of $1 \%$ leads to an increase in the informal economy of $0.86 \%$. Likewise, the coefficient associated with the agriculture variable is positive and significant at the $1 \%$ level. Indeed, an increase in the value added of agriculture to GDP of $1 \%$ leads to an increase in the size of the informal economy by $0.62 \%$. On the other hand, the coefficient associated with the level of education is negative and significant at the $1 \%$ level. A $1 \%$ increase in the enrollment rate leads to a decrease in the size of the informal economy by $0.22 \%$. Likewise, the coefficient associated with domestic credit is negative and significant at the $5 \%$ threshold. A $1 \%$ increase in credit leads to a $0.15 \%$ drop in informality. Specification 1 (column 2 ) presents the effects of urbanization on informality, taking into account the quality of institutions. It appears that in the presence of the variable quality of institutions, the positive effect of the urbanization rate on growth decreases. Indeed, the effect of the $1 \%$ increase in the urbanization rate on the size of the informal economy drops from $0.80 \%$ to $0.74 \%$. This therefore means that the quality of institutions plays a role in the relationship between urbanization and the informal economy. It also appears that the quality of institutions has a negative and significant effect on the size of the informal economy. Indeed, the coefficient associated with the institution variable is negative and significant at the $1 \%$ level. Thus, an improvement in the quality of institutions leads to a decrease in informality.

The research results therefore show that urbanization is a driver of the informal economy in the WAEMU countries. Urbanization, which manifests itself in the increase in the number of inhabitants of urban areas to the detriment of rural areas, also leads to increased unemployment in cities. In fact, the migrants who arrive in the cities, for the most part do not have the skills to be employed by formal companies, for positions of high responsibility. Most of them are therefore content with precarious jobs and others go into the informal sector in order to meet their needs. This therefore contributes to increasing the size of the informal economy. Notwithstanding these facts, this result confirms those of several authors such as Rei and Bhattacharya (2008), Gundogan and Bicerli (2009), and Elgin and Oyvat (2013).

Contrary to expectations, real GDP per capita has a positive effect on the size of the informal economy. This result, although unexpected, is validated by studies, in this case that of Ouédraogo (2017), with regard to the countries of sub-Saharan Africa. He explains this paradox by the fact that the participation of the informal 
sector in the formation of national income. In developing countries, such as those in sub-Saharan Africa, informal entrepreneurs do not operate completely in the shadows, as there are taxation systems in the informal sector. One of the reasons given to explain the development of informality is the level of the unemployment rate according to some authors. Torgler and Schneider (2007), Dreher and Schneider (2008) and Rei and Bhattacharya (2008) find empirical evidence that supports this hypothesis. Research also shows that an increase in agriculture's share of GDP increases the size of informality. This result is consistent with that of Torgler and Schneider (2009).

On the other hand, it also turns out that education can reduce informality. This result confirms that of Traoré (2016) who found in his study on Burkina Faso, using a general equilibrium model, that the higher the level of education of an individual, the less he will engage in activities Likewise, domestic credit has a negative effect on the size of the informal sector. Indeed, the credit granted by financial institutions is given to companies operating in the formal sector. Thus, an increase in these credits will encourage companies operating in the informal sector to formalize themselves in order to benefit from the financing. Also, access to bank credit could help small-scale informal enterprises whose turnover does not allow them to join the formal to increase their productivity and thus their turnover which would allow them to be formalized and thus reduce the size of the informal sector. This result is consistent with that of Rei and Bhattacharya (2008). It should also be noted that improving the quality of institutions hinders the development of informality. This result confirms those of Torger and Schneider (2009) and more recently by Maulida and Darwanto (2018). Also, it also emerges that in the presence of the quality of institutions, the effect of urbanization on the informal sector is attenuated. Which therefore leads us in the following to examine the possibility of a non-linear relationship between the informal economy, the rate of urbanization, and the quality of institutions.

\section{$\checkmark$ Robustness analysis}

We use the synthetic index of the informal economy to assess the robustness of our results to a change of proxy. The results are shown in columns 3 and 4 of Table 3 below. It appears that the effects of the different variables on the informal economy are the same regardless of the informality proxy used. We can therefore conclude that our results are robust.

Table 3: Results of the long-term analysis

\begin{tabular}{|c|c|c|c|c|}
\hline & (1) & (3) & (4) & (5) \\
\hline VARIABLES & EI & EI & ISEI & ISEI \\
\hline \multirow[t]{2}{*}{ ec } & $-0,427 * * *$ & $-0,449 * * *$ & $-0,370 * *$ & $-0,317 * *$ \\
\hline & $(0,126)$ & $(0,144)$ & $(0,155)$ & $(0,138)$ \\
\hline \multirow[t]{2}{*}{ Urbanization rate } & $0,800 * *$ & $0,742 * *$ & $1,352 *$ & $2,326 * * *$ \\
\hline & $(0,346)$ & $(0,318)$ & $(0,750)$ & $(0,676)$ \\
\hline \multirow[t]{2}{*}{ Real GDP per capita } & $1,65 \mathrm{e}-05^{* *}$ & $1,75 \mathrm{e}-05^{* *}$ & $0,000163 * * *$ & $0,000158 * * *$ \\
\hline & $(8,10 \mathrm{e}-06)$ & $(8,32 \mathrm{e}-06)$ & $(2,13 \mathrm{e}-05)$ & $(4,98 \mathrm{e}-05)$ \\
\hline \multirow[t]{2}{*}{ Taxation } & 0,0851 & 0,00965 & $1,727 * * *$ & $-0,646^{*}$ \\
\hline & $(0,205)$ & $(0,190)$ & $(0,580)$ & $(0,337)$ \\
\hline \multirow[t]{2}{*}{ Unemployment } & $0,864 *$ & $1,061 * *$ & $-0,371$ & $-1,718 * *$ \\
\hline & $(0,476)$ & $(0,493)$ & $(0,677)$ & $(0,715)$ \\
\hline \multirow[t]{2}{*}{ Education } & $-0,227 * * *$ & $-0,192 * * *$ & $-0,853 * * *$ & $-0,680 * * *$ \\
\hline & $(0,0588)$ & $(0,0547)$ & $(0,157)$ & $(0,133)$ \\
\hline \multirow[t]{2}{*}{ credit } & $-0,159 * *$ & $-0,255^{* * *}$ & $0,398 * * *$ & $0,587 * * *$ \\
\hline & $(0,0655)$ & $(0,0669)$ & $(0,146)$ & $(0,149)$ \\
\hline \multirow[t]{2}{*}{ Agriculture } & $0,628 * * *$ & $0,543 * * *$ & $1,690 * * *$ & $-0,341 *$ \\
\hline & $(0,134)$ & $(0,119)$ & $(0,337)$ & $(0,206)$ \\
\hline \multirow[t]{2}{*}{ Institutions } & & $-17,23 * *$ & & $-106,4 * * *$ \\
\hline & & $(7,624)$ & & $(23,82)$ \\
\hline \multirow[t]{2}{*}{ Constant } & 1,629 & $9,153 * * *$ & $-37,74$ & $9,803 * *$ \\
\hline & $(2,261)$ & $(3,364)$ & $(23,26)$ & $(4,972)$ \\
\hline Observations & 171 & 171 & & \\
\hline
\end{tabular}

Source: author using data from IMF (2018), WDI (2018) and WGI (2018)

Standard deviations are in parentheses

$(*),(* *),(* * *)$ Significant at $10 \%, 5 \%$ and $1 \%$ respectively 
$\checkmark$ Analysis of the non-linearity between the rate of urbanization, the informal economy and the quality of institutions

Table 4 presents the non-linear effects of urbanization on the size of the informal economy through the quality of institutions. The estimate shows that there is a level of institutional quality where urbanization and the size of informality have a negative relationship. Before this threshold there is a positive relationship between these two. This shows the need for nonlinear exploration. Indeed, the increase in the quality of institutions allows first of all a decrease in the rate of urbanization, because it makes it possible to reduce urbanization which aims to find jobs, by creating one of the sources of activity adapted to the rural environment (dam construction for market gardening, etc.). Secondly, the good quality of the institutions also allows the professional integration of new urbanites. It is therefore easy to understand that improving the quality of institutions reduces the effect of urbanization on the size of the informal economy.

We also perform a robustness analysis using another indicator of the size of the informal economy, namely the Synthetic Index of the Informal Economy (ISEI). The results of the estimate recorded in column 2 of Table X confirm the previous analysis. Indeed, there is still evidence that an improvement in the quality of institutions reduces the effect of urbanization on the size of the informal economy.

Table 4: Result of the nonlinear analysis

\begin{tabular}{|c|c|c|}
\hline VARIABLES & $\begin{array}{l}(1) \\
\text { EI }\end{array}$ & $\begin{array}{l}\text { (2) } \\
\text { ISSI }\end{array}$ \\
\hline Real GDP per capita & $\begin{array}{l}4,06 \mathrm{e}-05 * * * \\
(9,26 \mathrm{e}-06)\end{array}$ & $\begin{array}{l}4,55 \mathrm{e}-05 * * * \\
(1,50 \mathrm{e}-05)\end{array}$ \\
\hline Taxation & $\begin{array}{l}-0,348 * * * \\
(0,0754)\end{array}$ & $\begin{array}{l}-0,454 * * * \\
(0,122)\end{array}$ \\
\hline Unemployment & $\begin{array}{l}-0,605 * * * \\
(0,144)\end{array}$ & $\begin{array}{l}-1,345^{* * *} \\
(0,232)\end{array}$ \\
\hline Education & $\begin{array}{l}-0,0359 \\
(0,0283)\end{array}$ & $\begin{array}{l}-0,0583 \\
(0,0457)\end{array}$ \\
\hline Crédit intérieur & $\begin{array}{l}-0,200 * * * \\
(0,0395)\end{array}$ & $\begin{array}{l}-0,313 * * * \\
(0,0638)\end{array}$ \\
\hline Agriculture & $\begin{array}{l}-0,0498 \\
(0,0582)\end{array}$ & $\begin{array}{l}-0,0681 \\
(0,0941)\end{array}$ \\
\hline Urbanization rate & $\begin{array}{l}0,132^{*} \\
(0,102)\end{array}$ & $\begin{array}{l}0,133^{*} \\
(0,165)\end{array}$ \\
\hline Urbanization rate & $\begin{array}{l}-0,242 * * \\
(0,103)\end{array}$ & $\begin{array}{l}-0,048^{*} \\
(0,167)\end{array}$ \\
\hline Constant & $\begin{array}{l}65,36^{* * *} \\
(3,516)\end{array}$ & $\begin{array}{l}24,48 * * * \\
(5,684)\end{array}$ \\
\hline Observations & 189 & 189 \\
\hline $\mathrm{R}^{2}$ & 0,639 & 0,377 \\
\hline Number of countries & 7 & 7 \\
\hline
\end{tabular}

\section{Conclusion}

This research aimed to determine the relationship (direct and not direct) between the rate of urbanization and informality in the UEMOA zone, by formulating the hypothesis that the latter may be affected by the level of institutional quality. The observations cover the period 1991-2017. The results of the dependence tests having shown inter-individual independence, we stuck to the first generation stationarity tests, which shows that some study variables are not stationary at level, we then proceeded to a test of first generation cointegration namely Pedroni (1999). The results of the latter show that the variables used are cointegrated. These results of the tests on the data therefore led us to estimate our direct relationship using the pooled mean group (PMG) method. And for the nonlinear analysis between urbanization and informality conditioned by the quality of institutions, we opt for a regime change model.

Our results show that the rate of urbanization has a positive effect on the informality of the countries of the WAEMU zone. It also appears that the quality of institutions affects this relationship. Indeed, we find that if the quality of institutions reaches 0.57 then the urbanization rate decreases so that the informal economy does not increase any more. It also emerges that the unemployment rate and the real GDP per capita positively affect the 
size of the informal economy, on the other hand the level of education and domestic credit negatively affect the latter. This research shows that in order to reduce informality in the countries of the zone, all other things being equal, political decision-makers will have to improve the quality of institutions, which would make it possible to create off-season activities in order to allow populations find income-generating activities in rural areas, which would reduce urbanization linked to the search for subsistence employment.

\section{Bibliographie}

Banerjee, B. (1983). The role of the informal sector in the migration process:a test of probabilistic migration models and labour market segmen-tation for India. Oxford Economic Papers, 35, 399-422.

Bayale, N. (2018). Aide et Croissance dans les pays de l'Union Economique et Monétaire Ouest Africaine (UEMOA): retour sur une relation controversée [Aid and Growth in West African Economic and Monetary Union (WAEMU) countries: a return back to a controvecontroversial relat.

Botero, J. C., Djankov, S., \& La, P. R. (2004). The regulation of labor. The Quarterly Journal of Economics, $119(4), 1339-1382$.

Choi, J. P., \& Thum, M. (2005). Corruption and the shadow economy. International Economic Review, 46(3), 817-836.

Cole, W. E., \& Sanders, R. D. (1985). Internal migration and urbaniza-tion in The Third World. American Economic Review , 75, 481-493.

Dreher, A., \& Schneider, F. (2010). Corruption and the shadow economy: an empirical analysis. Public Choice, 144(1-2), 215-238.

Elgin, C., \& Oyvat, C. (2013). Lurking in the cities: Urbanization and the informal economy. Structural Change and Economic Dynamics, 27, 36-47.

Frees, E. .. (n.d.). Assessing cross-sectional correlation in panel data. Journal of econometrics, 69(2), 393-414.

Friedman, M. (1937). The use of ranks to avoid the assumption of normality implicit in the analysis of variance. Journal of the american statistical association, 32(200), 675-701.

Galli, R., \& Kucera, D. (2004). Labor standards and informal employment in Latin America. World Development, 32(5), 809-828.

Gundogan, N., \& Bicerli, M. K. (2009). « Urbanisation et informalité du marché du travail dans les pays en développement ». MPRA Paper 18247, Bibliothèque universitaire de Munich, Allemagne.

Hansen, B. E. (1999). Threshold effects in non-dynamic panels: Estimation, testing, and inference. Journal of econometrics, 93(2), 345-368.

Im, K. S., Pesaran, M. H., \& Shin, Y. (2003). Testing for unit roots in heterogeneous panels. Journal of econometrics, 115(1), 53-74.

Johnson, S., Kaufmann, D., \& Zoido-Lobatón, P. (2000). orruption, public finances and the unofficial economy. World Bank Publications, 2169.

Lipton, M. (1976). Why Poor People Stay Poor: Urban Bias in World Development. Harvard University Press, Cambridge, $M A$.

Medina, L., \& Schneider, F. (2018). Shadow economies around the world: what did we learn over the last 20 years? IMF Working Papers.

MONDIALE, B. (2017). Mettre fin à l'extrême pauvreté et Promouvoir une prospérité partagée. Rapport annuel.

Ouédraogo, I. M. (2017). Governance, corruption, and the informal economy. Modern Economy, 8(02), 256.

Pesaran, H. M. (2004). General Diagnostic Tests for Cross Section Dependence in Panels. Cambridge University Working Paper, 0435.

Rauch, J. E. (1993). Economic development, urban underemployment, and income inequality. Canadian Journal of Economics, 26(4), 901-918.

Rei, D., \& Bhattacharya, M. (2008). The impact of institutions and policy on informal economy in developing countries: an econometric exploration. ILO.

Safa, H. I. (1986). Urbanization, the informal economy and state policy in Latin America. Urban Anthropology and Studies of Cultural Systems and World Economic Development, , 135-163.

Shleifer, A., \& Vishny, R. W. (1993). Corruption. The quarterly journal of economics. 108(3), 599-617.

Todaro, M. (1969). A model of labor migration and urban unemploymentin less developed countries. American Economic Review , 69, 486-499.

Todaro, M. P. (1997). Urbanization, unemployment and migration in Africa: theory and policy.

Torgler, B., \& Schneider, F. (2009). The impact of tax morale and institutional quality on the shadow economy. Journal of Economic Psychology, 30(2), 228*245.

Vinay Lall, S., Vernon Henderson, j., \& Venables, A. J. (2017). Ouvrir les Villes Africaines. Groupe Banque Mondiale. 
Appendices
Table 1: Result of dependency analysis

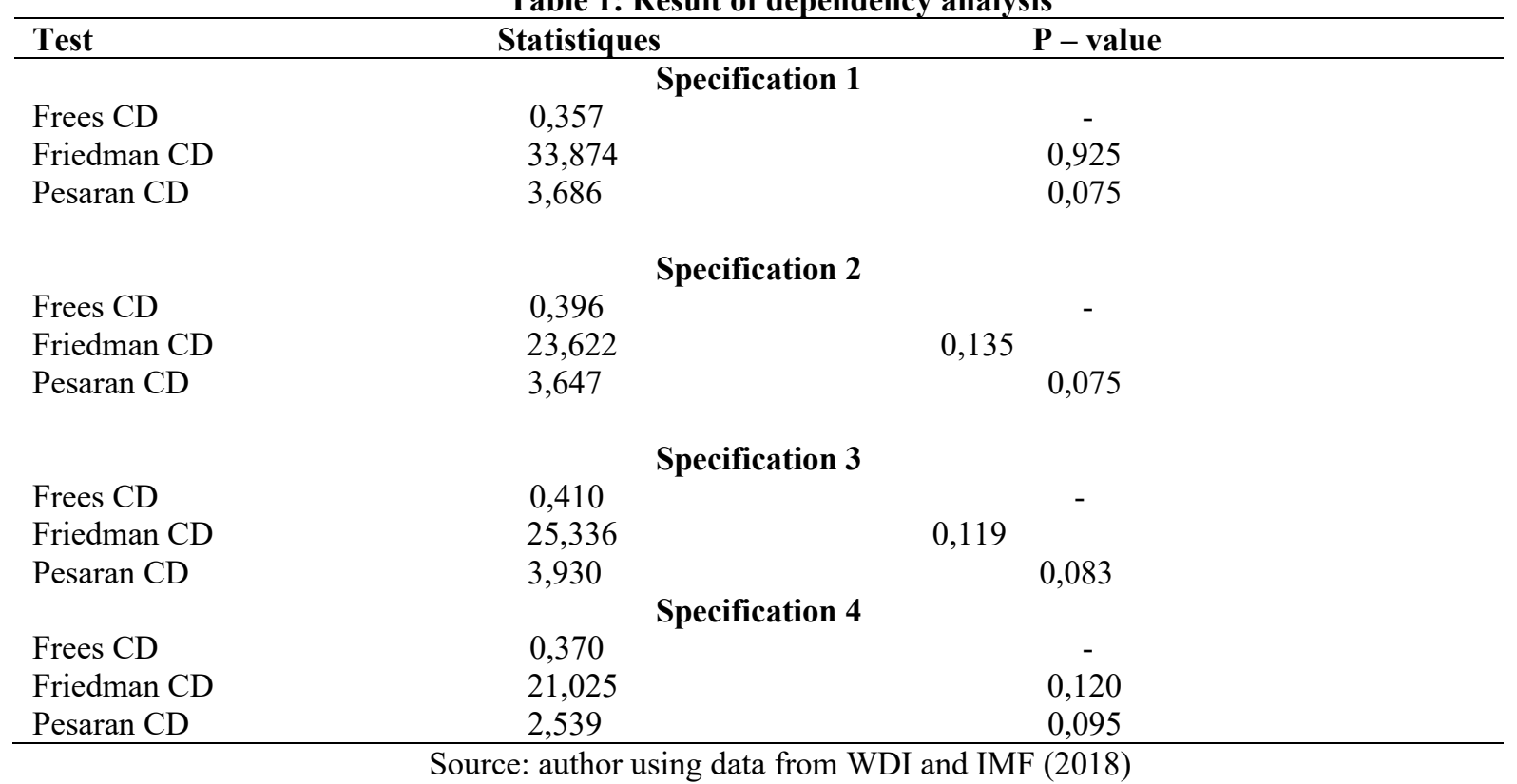

Table 2: Unit root test results

\begin{tabular}{|c|c|c|c|c|}
\hline \multirow[t]{2}{*}{ Variables } & \multicolumn{2}{|l|}{ Niveau } & \multicolumn{2}{|c|}{ Différence Première } \\
\hline & IPS & LLC & IPS & LLC \\
\hline IE & $\begin{array}{l}-1,397^{*} \\
(0,0812)\end{array}$ & $\begin{array}{l}-2,003 * * \\
(0,022)\end{array}$ & $\begin{array}{l}-3,396^{* * *} \\
(0,000)\end{array}$ & $\begin{array}{l}-12,452 * * * \\
(0,000)\end{array}$ \\
\hline UR & $\begin{array}{l}3,93916 \\
(1,0000)\end{array}$ & $\begin{array}{l}15,849 \\
(1,000)\end{array}$ & $\begin{array}{l}-3,58873 * * * \\
(0,000)\end{array}$ & $\begin{array}{l}-1,838 * * \\
(0,033)\end{array}$ \\
\hline Credit & $\begin{array}{l}5.752 \\
(1.000)\end{array}$ & $\begin{array}{l}4.969 \\
(1.000)\end{array}$ & $\begin{array}{l}-2.341 * * * \\
(0.009)\end{array}$ & $\begin{array}{l}-4.232 * * * \\
(0.000)\end{array}$ \\
\hline INST & $\begin{array}{l}-1.287^{*} \\
(0,098)\end{array}$ & $\begin{array}{l}-2.106^{*} \\
(0.017)\end{array}$ & $\begin{array}{l}-3.655^{* * * *} \\
(0.000)\end{array}$ & $\begin{array}{l}-5.437 * * * \\
(0.000)\end{array}$ \\
\hline GDPh & $\begin{array}{l}-3,517 \\
(0,999)\end{array}$ & $\begin{array}{l}-1,427 \\
(0,923)\end{array}$ & $\begin{array}{l}-8,62831 * * * \\
(0,000)\end{array}$ & $\begin{array}{l}-6,244 * * * \\
(0,000)\end{array}$ \\
\hline TAX & $\begin{array}{l}4,216 \\
(1,000)\end{array}$ & $\begin{array}{l}2,57839 \\
(0,9950)\end{array}$ & $\begin{array}{l}-5,22673 \\
(0,000)\end{array}$ & $\begin{array}{l}-9,029 * * * \\
(0,0000)\end{array}$ \\
\hline EDU & $\begin{array}{l}0,81106 \\
(0,7913)\end{array}$ & $\begin{array}{l}-2,135 * * \\
(0,0311)\end{array}$ & $\begin{array}{l}-2,13472 * * * \\
(-2,1347)\end{array}$ & $\begin{array}{l}-2,85798 * * * \\
(0,002)\end{array}$ \\
\hline Unemployment & $\begin{array}{l}-0,02046 \\
(0,4918)\end{array}$ & $\begin{array}{l}0,142 \\
(0,556)\end{array}$ & $\begin{array}{l}-3,51965^{* * *} \\
(0,000)\end{array}$ & $\begin{array}{l}-4,782 * * * \\
(0,000)\end{array}$ \\
\hline
\end{tabular}

Source: author using data from IMF (2018), WDI (2018) and WGI (2018)

Standard deviations are in parentheses

$(*),(* *),(* * *)$ Significant at $10 \%, 5 \%$ and $1 \%$ respectively 
Table 3: Result of the cointegration test

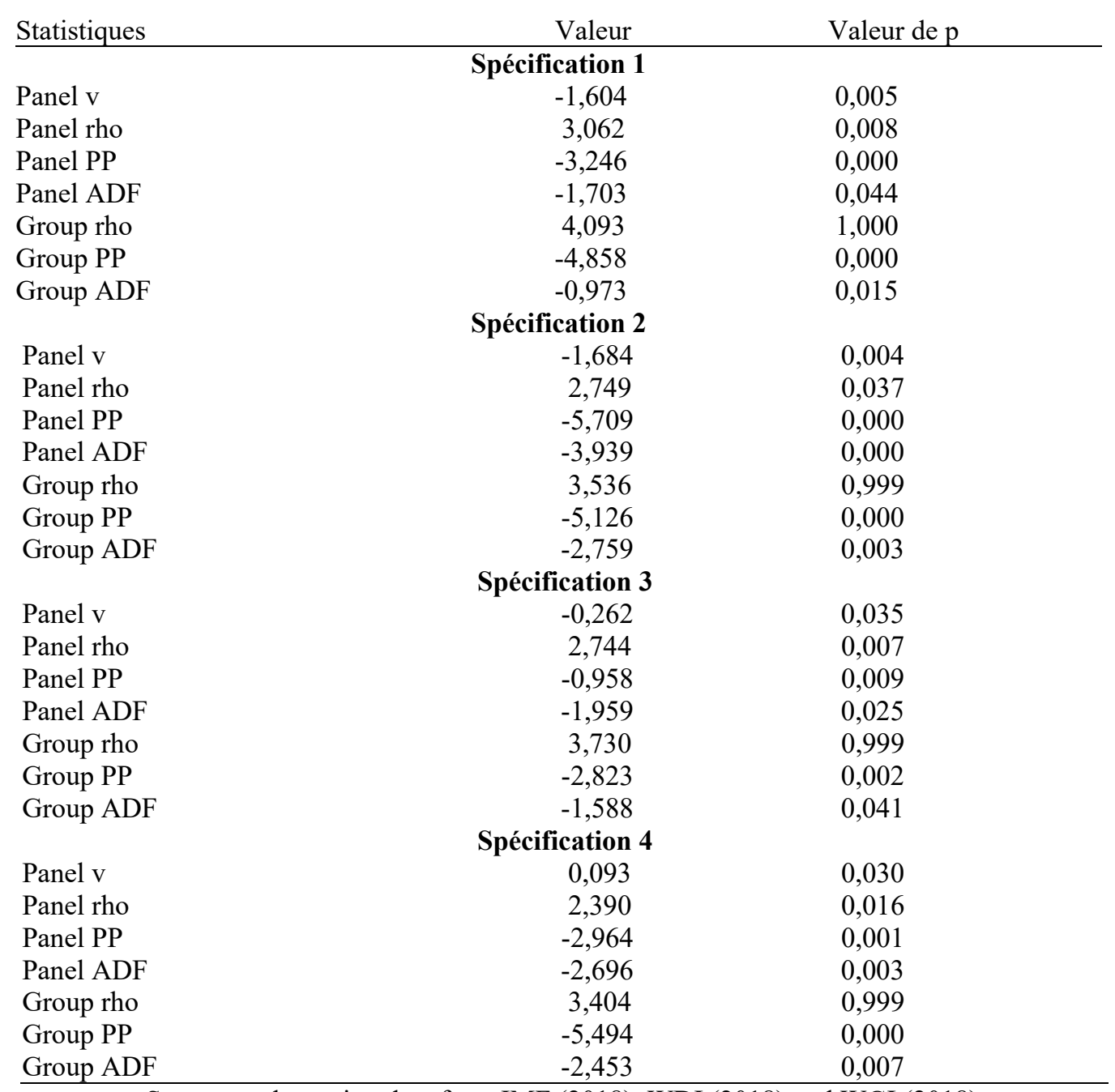

Source: author using data from IMF (2018), WDI (2018) and WGI (2018)

Standard deviations are in parentheses

$(*),(* *),(* * *)$ Significant at $10 \%, 5 \%$ and $1 \%$ respectively

Table 4: Result of Hausman tests Specification 1 :

\begin{tabular}{lllll}
\hline Variables & $\mathrm{mg}$ & $\mathrm{pmg}$ & Difference & $\mathrm{S}, \mathrm{E}$, \\
\hline UR & 2,659 & $-1,847$ & 4,506 & 10,707 \\
GDP & $-0,0001$ & $-0,0016$ & $-0,004$ & 0,004 \\
TAX & 3,424 & $-0,580$ & 4,004 & 10,756 \\
Unemployment & 52,033 & $-0,501$ & 52,534 & 193,63 \\
Credit & $-0,5344$ & $-0,299$ & $-0,235$ & 4,064 \\
EDU & $-0,9755$ & 0,3427 & $-1,318$ & 2,765 \\
Agriculture & $-0,1364$ & 0,0189 &,- 155 & 1,611 \\
\hline
\end{tabular}

Test: Ho: difference in coefficients not systematic

$$
\begin{aligned}
\operatorname{chi} 2(6) & =(b-B)^{\prime}\left[\left(V_{-} b-V_{-} B\right)^{\wedge}(-1)\right](b-B) \\
& =10,03 \\
\text { Prob }>\text { chi } 2 & =0,185
\end{aligned}
$$

Source: author using data from IMF (2018), WDI (2018) and WGI (2018) 
Specification 2

\begin{tabular}{lllll}
\hline Variables & $\mathrm{mg}$ & $\mathrm{pmg}$ & Difference & $\mathrm{S}, \mathrm{E}$, \\
\hline UR & 2,325 & 0,582 & 1,743 & 4,998 \\
GDP & $-0,0007$ & 0,0002 & $-0,0001$ & 0,0002 \\
TAX & 1,060 & 0,0447 & 1,016 & 2,187 \\
Unemployment & 20,948 & $-1,214$ & 22,163 & 55,413 \\
Credit & 0,493 & 0,3195 & 0,174 & 0,4562 \\
EDU & $-0,499$ & $-0,188$ & $-0,311$ & 0,412 \\
Agriculture & $-0,1364$ & 0,0189 &,- 155 & 1,611 \\
INST & 5,050 & $-35,634$ & 40,683 & 102,979 \\
\hline
\end{tabular}

Test: Ho: difference in coefficients not systematic

$$
\begin{aligned}
\operatorname{chi} 2(7) & =(b-B)^{\prime}\left[\left(V_{-} b-V \_B\right)^{\wedge}(-1)\right](b-B) \\
& =4,22
\end{aligned}
$$

Prob $>$ chi $2=0,7541$

Source: author using data from IMF (2018), WDI (2018) and WGI (2018) Specification 3

\begin{tabular}{lrrrr}
\hline Variables & \multicolumn{2}{c}{ pmg } & \multicolumn{1}{c}{ Difference } & S.E. \\
\hline TU & 2,743735 & 1,351978 & 1,391757 & 10,40301 \\
PIBh & $-0,0000187$ & 0,0001629 & $-0,0001816$ & 0,0003462 \\
TAX & 2,881382 & 1,726939 & 1,154443 & 4,936189 \\
TC & $-117,0601$ & $-0,370886$ & $-116,6892$ & 273,0105 \\
Primaire & $-0,6767582$ & $-0,8528581$ & 0,1760999 & 0,6043085 \\
CI & 0,6069564 & 0,3978867 & 0,2090697 & 1,092265 \\
AGRI & 0,698635 & 1,690395 & $-0,99176$ & 1,316114 \\
\hline
\end{tabular}

Test: Ho: difference in coefficients not systematic $\operatorname{chi} 2(6)=(b-B)^{\prime}\left[\left(V_{-} b-V_{-} B\right)^{\wedge}(-1)\right](b-B)$ $=2,04$

Prob $>$ chi2 $=0,9163$

Source: author using data from IMF (2018), WDI (2018) and WGI (2018) Specification 4

\begin{tabular}{lllll}
\hline Variables & $\mathrm{mg}$ & $\mathrm{pmg}$ & Difference & S.E. \\
\hline UR & 3.955477 & 2.325677 & 1.6298 & 15.08509 \\
GDP & -.0001145 & .0001579 & -.0002724 & .0004394 \\
TAX & 3.016603 & -.6461956 & 3.662798 & 6.161968 \\
Unemployment & -107.6233 & -1.718297 & -105.905 & 329.419 \\
Credit & -.8308491 & -.6795388 & -.1513103 & .8232221 \\
EDU & .6739105 & .5868708 & .0870397 & 1.493246 \\
Agriculture & .6595411 & -.3413399 & 1.000881 & 1.514463 \\
INST & 18.33929 & -106.4077 & 124.747 & 121.8117 \\
\hline
\end{tabular}

Test: Ho: difference in coefficients not systematic chi2(6) $=(b-B)^{\prime}\left[\left(V_{-} b-V_{-} B\right)^{\wedge}(-1)\right](b-B)$

$=10,03$

Prob $>$ chi $2=0,185$

Source: author using data from IMF (2018), WDI (2018) and WGI (2018) 
Table 5: Result of the linearity test

\begin{tabular}{ll}
\hline Interaction variables & Inst \\
\hline Two regimes (single threshold) & \\
threshold $\hat{\gamma}_{1}$ & 0,575 \\
IC $(95 \%)$ & {$[0,571 ; 0,577]$} \\
LR-test (p-value) & $27,30(0,016)$ \\
\hline Three regimes (two thresholds) & \\
\multicolumn{1}{c}{$\hat{\gamma}_{2}$} & 0,478 \\
threshold & \\
IC $(95 \%)$ & {$[0,476 ; 0,480]$} \\
LR-test (p-value) & $3,97(0,903)$ \\
\hline ce: author using data from IMF (2018), WDI $(2018)$ and WGI
\end{tabular}

Source: author using data from IMF (2018), WDI (2018) and WGI (2018) 